\title{
Case Report \\ Growth Hormone Deficiency in a Case of Crouzon Syndrome with Hydrocephalus
}

\author{
Mei-Hong Wen, ${ }^{1,2}$ Hui-Pin Hsiao, ${ }^{2,3}$ Mei-Chyn Chao,, ${ }^{2,4}$ and Fuu-Jen Tsai ${ }^{5}$ \\ ${ }^{1}$ Department of Pediatrics, Kaohsiung Municipal United Hospital, Kaohsiung 813, Taiwan \\ ${ }^{2}$ Division of Genetics, Endocrinology and Metabolism, Department of Pediatrics, Kaohsiung Medical University Hospital, \\ Kaohsiung 807, Taiwan \\ ${ }^{3}$ Department of Pediatrics, Kaohsiung Municipal Hsiao Kang Hospital, Kaohsiung 812, Taiwan \\ ${ }^{4}$ Department of Medical Genetics, College of Medicine, Kaohsiung Medical University, \\ Kaohsiung 807, Taiwan \\ ${ }^{5}$ School of Post-baccalaureate Chinese Medicine, Department of Medical Genetics, China Medical University, Taichung 404, Taiwan
}

Correspondence should be addressed to Mei-Chyn Chao, mcchao@kmu.edu.tw

Received 18 December 2009; Accepted 27 March 2010

Academic Editor: Xiaoping Luo

Copyright ( $\odot 2010$ Mei-Hong Wen et al. This is an open access article distributed under the Creative Commons Attribution License, which permits unrestricted use, distribution, and reproduction in any medium, provided the original work is properly cited.

\begin{abstract}
Crouzon syndrome is one of the most common craniofacial syndromes and is inherited as autosomal dominant with variable expression. We report an 11 and a half-year-old boy with Crouzon syndrome with severe growth retardation. He had hydrocephalus since infancy and recently suffered from frequent dizziness. His bone age was only 5 years according to the Greulich and Pyle atlas. Magnetic resonance imaging showed shallow orbits, obstructive hydrocephalus, and cerebellar tonsil herniation. Growth hormone provocative tests revealed a reduced peak growth hormone response in both insulin and clonidine tests. Severe iron deficiency anemia was noted at the same time. Molecular analysis identified a common mutation point of Cys278Phe for Crouzon syndrome in exon IIIa of the fibroblast growth factor receptor 2 (FGFR2) gene. Since growth retardation is not a common feature of Crouzon syndrome, we reviewed the literature for the incidence of hydrocephalus in Crouzon syndrome and the association with growth hormone deficiency.
\end{abstract}

\section{Introduction}

In 1912, Crouzon described a syndrome that consisted of brachycephaly, shallow orbits, and maxillary hypoplasia [1]. Since then, craniofacial syndromes have been subcategorized into over a hundred syndromes based on the severity of the craniofacial and associated congenital malformations [2]. Crouzon syndrome, along with Apert, Carpenter, Chotzen, and Pfeiffer syndromes, is one of the most common genetic disorders associated with a craniofacial syndrome. Other facial deformities in Crouzon syndrome may include prominent nose, frontal bossing, and ocular proptosis due to shallow orbits with or without hypertelorism, although agerelated phenotype modifications have been reported [3].

Patients of Crouzon syndrome may occasionally present with hydrocephalus, seizures, and mental retardation. The incidence of hydrocephalus in craniosynostosis ranges from
$4 \%$ to $26 \%[4,5]$. Nonetheless, short stature with growth hormone deficiency (GHD) and/or iron deficiency anemia (IDA) have rarely been reported in the literature. Here we report a case of Crouzon syndrome with hydrocephalus, also presenting with severe short stature due to GHD and IDA.

\section{Case Report}

An 11 and a half-year-old boy visited our out-patient clinic for frequent dizziness and marked growth retardation. He was a case of Crouzon syndrome which had been suspected since infancy. The positive facial features were brachycephaly, hypoplasia maxilla, severe ocular proptosis (Hertel's exophthalmometry measuring 22-23 mm on both eyes) with hypertelorism, and low-set ears. He had a 3200 gm birth weight and was born to a generally healthy 
130
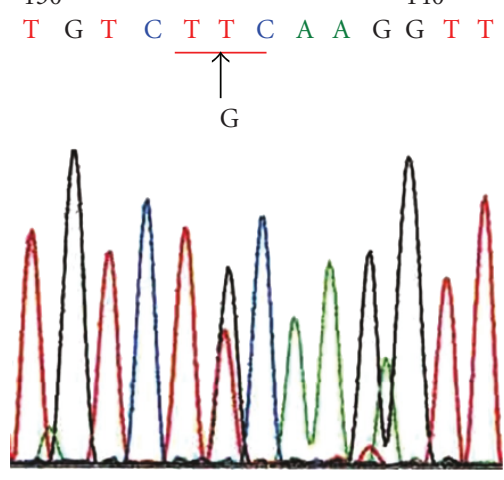

FIGURE 1: Direct sequencing data indicated that this patient carries the Cys278Phe mutation in the exon IIIa of FGFR2 gene.

mother via NSD at 40 wks' gestational age. Owing to severe hydrocephalus and cerebellar tonsil herniation (Chiari I malformation) revealed by magnetic resonance imaging (MRI), he had endoscopic third ventriculostomy and shunt at the age of 13 months. Six months later, he received frontal advancement and ventricular shunting because of a progressive increase in ventricular size and rising intracranial pressure (ICP). His head circumference remained at around the 50th percentile, but he had frequent respiratory tract infections during early childhood.

The patient had not been followed up regularly after the age of 6 years until recently. His chief complaint was frequent dizziness and marked growth retardation. He was $18.5 \mathrm{~kg}$ and $111.2 \mathrm{~cm}$, which represented -3 standard deviation (SD) in body weight and $-5 \mathrm{SD}$ in height of his age. His brother, who is 4 and a half years older, was $182 \mathrm{~cm}$. His parents are grossly normal and the mid-parent height is $168 \mathrm{~cm}$. On admission, his general condition was stable and intelligence quotient (IQ) around 90. The external genital organ was in the prepuberal stage. Chromosome analysis was normal in G-banding karyotype; however, molecular analysis identified a common mutation point of Cys278Phe in exon IIIa of the fibroblast growth factor receptor 2 (FGFR2) gene (Figure 1). His bone age was only $4.5-5$ years according to the Greulich and Pyle atlas (Figure 2), which was a 6.5-7-year delay. Skull radiography showed a shallow and elongated sella turcica. MRI revealed obstructive hydrocephalus of both lateral ventricles with an interruption of pituitary stalk, shallow orbits, and Chiari I malformation. Pituitary height was $5.6 \mathrm{~mm}$ in midsagittal T1-weighted spin-echo MRI (Figure 3), which was around mean according to Tsunoda's study [6]. A biochemistry profile revealed thyroid hormones and cortisol within normal limits, but blood routine showed microcytic anemia. A growth hormone provocative test revealed a reduced peak growth hormone response of $4.57 \mathrm{uIU} / \mathrm{mL}$ in the insulin test and $2.63 \mathrm{uIU} / \mathrm{mL}$ in the clonidine test. The concentrations of insulin-like growth factor 1 (IGF-I) and insulin-like growth factor binding protein 3 (IGF-BP3) were also very low (IGF-I $<10.0 \mathrm{ng} / \mathrm{mL}$, IGFBP-3 $: 1.5 \mu \mathrm{g} / \mathrm{mL}$ ).

Severe iron deficiency anemia without thalassemia was noted (hemoglobin: $8.8 \mathrm{~g} / \mathrm{dL}, \mathrm{RBC}$ : 4.18 million/ul, MCV:

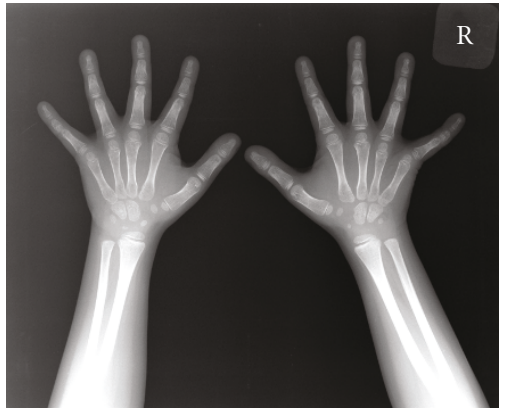

FIGURE 2: The patient's bone age was only $4.5-5$ years according to the Greulich and Pyle atlas.

$68.2 \mathrm{fL}$; serum iron: $7 \mathrm{mg} / \mathrm{dL}$, ferritin: $4 \mathrm{ng} / \mathrm{mL}$, UIBC: $525 \mathrm{mg} / \mathrm{dL}$ ) with regards to the microcytic anemia. Iron supplements at a dose of $100 \mathrm{mg} /$ day were subscribed immediately. Human growth hormone (HGH) subcutaneous replacement at a dose of $0.3 \mathrm{mg} / \mathrm{kg} /$ week in seven divided doses was also subscribed, and the growth velocity was $3 \mathrm{~cm}$ per year during the first half year. After his hemoglobin and serum iron levels gradually returned to normal, his dizziness disappeared and his growth velocity increased to $5 \mathrm{~cm}$ per year under HGH therapy.

\section{Discussion}

We reviewed the literature for the incidence of hydrocephalus in Crouzon syndrome and the association with GHD, only one case report: "Crouzon syndrome with short stature due to partial GHD" [7] was found. However, with the progressive improvement and higher usage of imaging studies, cases of the incidence of hydrocephalus in Crouzon syndrome are not uncommon. From Proudman's large study of central nervous system imaging in Crouzon syndrome performed in South Australia [8], ventriculomegaly was present in $51 \%$ of available reviewed cases. Most of those taken with follow-up computed tomographic scans were nonprogressive, even in cases of severe ventriculomegaly (hydrocephalus). There are various theories about the mechanism of hydrocephalus. In Noetzel's study [9], he suggests that hydrocephalus occurs secondary to the defective formation of the cranium, so it is reasonable that in many cases the hydrocephalus is nonprogressive. Most ventriculomegaly in Crouzon syndrome is asymptomatic and does not necessitate any treatment, unless there is a clear evidence of significantly raised intracranial pressure. Fronto-orbital advancement and shunt system are treatments of choice [8].

In our report case, GHD may have resulted in this patient's growth retardation, which is not a common finding in Crouzon syndrome. Does GHD result from hydrocephalus? There have been a few reports of endocrine disorders in children with shunted hydrocephalus, such as sexual precocity $[10,11]$ or decreased basal levels of GH and IGF-1 [12]. Increased intracranial pressure has been perceived as a possible cause of pituitary dysfunction. In a series of papers by Löppönen et al. [13-16], the growth pattern 


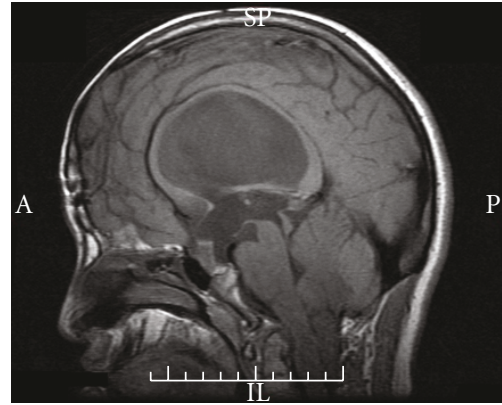

FIGURE 3: MRI revealed obstructive hydrocephalus of both lateral ventricles, shallow orbits, and cerebellar tonsil herniation (Chiari I malformation). Pituitary height was $5.6 \mathrm{~mm}$ in midsagittal T1weighted spin-echo MRI.

of 114 children with shunted hydrocephalus was analyzed. It was characterized by slow linear growth in prepuberty, accelerated physical maturation during puberty, and reduced final height [13]. This has also been shown to be associated with accelerated pubertal development in both boys and girls [14]. Furthermore, they studied these patients' serum growth hormone, plasma IGF-1, and IGFBP-3 concentrations. They concluded that reduced growth hormone secretion may contribute to the pattern of slow linear growth and reduced final height observed in these patients [15]. Since there was an association with growth hormone, Löppönen et al. designed a study performing radiography of the sella turcica, MRI of the pituitary gland, and pituitary hormone stimulation tests in a subgroup of this large series (54 out of 114) to assess pituitary size and functional capacity [16]. The results indicated that children with shunted hydrocephalus had an increased pituitary size on average. About onethird of these patients had signs of reduced GH secretion and a significantly lower pituitary height, which probably contributed to their poor linear growth. Increased pituitary size was associated with enhanced gonadotrophin secretion, which may result in early puberty in children with shunted hydrocephalus.

Another review article about disorders of growth and puberty in children with nontumoral hydrocephalus had similar results [17]. They concluded that central early puberty was the most frequent endocrine disorder in 21 out of 31 patients. In their cases, short stature was frequently due to meningomyelocele and rarely to GH deficiency.

In our case, the pituitary height in MRI was not smaller than normal for his age, but an interruption of the pituitary stalk was found. He was only found to have GHD but no signs of early puberty. His hydrocephalus and Chiari I malformation were stationary except for the shallow orbits becoming more prominent. He had severe proptosis but his visual acuity was normal. Although Chiari I malformation could also cause headache or dizziness [18], his dizziness might have been caused by severe IDA, since the symptoms disappeared after anemia correction. The results of $\mathrm{HGH}$ treatment were not satisfactory during the first half year, but became better after IDA had been corrected. Therefore, besides the compliance and method of HGH injection, other underlying diseases should be considered and treated if the therapeutic effect is not as expected.

Is there any association between GHD and Chiari I malformation? Tubbs et al. reported a study which showed that a small group of children with GHD had small posterior fossa, which was similar to the features of Chiari patients [19]. They hypothesized that GHD might lead to Chiari I malformation through the underdevelopment of the posterior fossa. In one of their following case studies [20], by presenting the case of 3 brothers, 2 with GHD and Chiari, and one with neither, they provided evidence of this. Therefore, it would be interesting to see if $\mathrm{HGH}$ therapy leads to the improvement of Chiari malformation. Although surgery is not necessary in our case so far, we hope to see HGH therapy contributes to improvement of Chiari malformation by the annual MRI survey.

The diagnosis of Crouzon syndrome is usually made by the patients' clinical signs, including acrocephaly, orbital proptosis, midfacial hypoplasia with "parrot-beak" nose, short upper lip, high narrow palate, narrowly spaced teeth, and prognathism [21]. To date, most patients have been shown to carry mutations of the FGFR2 gene [22]. In Chiang's mutation analysis of Crouzon syndrome in Taiwanese patients, three of the 12 patients carried the Cys342Arg mutation, which is the most frequent mutation found in Taiwanese patients. The second most common, as in our case, is the Cys278Phe mutation [23]. Molecular analysis of the FGFR2 gene can help to confirm and classify the diagnosis of craniosynostosis syndrome.

\section{References}

[1] K. L. Jones, Smith's Recognizable Patterns of Human Malformation, Elsevier Saunders, 2006.

[2] R. M. Winter and M. Baraitser, The London Dysmorphology Database, Oxford University Press, Oxford, UK, 1994.

[3] T. Maeda, M. Hatakenaka, H. Muta, et al., "Clinically mild, atypical, and aged craniofacial syndrome is diagnosed as Crouzon syndrome by identification of a point mutation in the fibroblast growth factor receptor 2 gene (FGFR2)," Internal Medicine, vol. 43, no. 5, pp. 432-435, 2004.

[4] M. Golabi, M. S. B. Edwards, and D. K. Ousterhout, "Craniosynostosis and hydrocephalus," Neurosurgery, vol. 21, no. 1, pp. 63-67, 1987.

[5] A. Hanieh, R. Sheen, and D. J. David, "Hydrocephalus in Crouzon's syndrome," Child's Nervous System, vol. 5, pp. 188$189,1989$.

[6] A. Tsunoda, O. Okuda, and K. Sato, "MR height of the pituitary gland as a function of age and sex: especially physiological hypertrophy in adolescence and in climacterium," American Journal of Neuroradiology, vol. 18, no. 3, pp. 551-554, 1997.

[7] C. R. Feild, A. Leiber, and C. Toniges, "Case report: crouzon syndrome with short stature," American Journal of the Medical Sciences, vol. 302, no. 2, pp. 101-102, 1991.

[8] T. W. Proudman, B. E. Clark, M. H. Moore, A. H. Abbott, and D. J. David, "Central nervous system imaging in Crouzon's syndrome," Journal of Craniofacial Surgery, vol. 6, no. 5, pp. 401-405, 1995.

[9] M. J. Noetzel, J. L. Marsh, H. Palkes, and M. Gado, "Hydrocephalus and mental retardation in craniosynostosis," Journal of Pediatrics, vol. 107, no. 6, pp. 885-892, 1985. 
[10] Y. Tomono, Y. Maki, M. Ito, and Y. Nakada, "Precocious puberty due to postmeningitic hydrocephalus," Brain and Development, vol. 5, no. 4, pp. 414-417, 1983.

[11] L. Perrone, D. Del Gaizo, E. D’Angelo, L. Rea, G. Di Manso, and R. Del Gado, "Endocrine studies in children with myelomeningocele," Journal of Pediatric Endocrinology, vol. 7, no. 3, pp. 219-223, 1994.

[12] L. Leveratto, P. Picco, A. Cama, et al., "Insulin like growth factor I (IGF1) in children with neural tube closure defects: a preliminary report," European Journal of Pediatric Surgery, vol. 3, supplement 1, pp. 19-20, 1993.

[13] T. Löppönen, A.-L. Saukkonen, W. Serlo, P. Lanning, and M. Knip, "Slow prepubertal linear growth but early pubertal growth spurt in patients with shunted hydrocephalus," Pediatrics, vol. 95, no. 6, pp. 917-923, 1995.

[14] T. Löppönen, A.-L. Saukkonen, W. Serlo, P. Tapanainen, A. Ruokonen, and M. Knip, "Accelerated pubertal development in patients with shunted hydrocephalus," Archives of Disease in Childhood, vol. 74, no. 6, pp. 490-496, 1996.

[15] T. Löppönen, A.-L. Saukkonen, W. Serlo, P. Tapanainen, A. Ruokonen, and M. Knip, "Reduced levels of growth hormone, insulin-like growth factor-I and binding protein-3 in patients with shunted hydrocephalus," Archives of Disease in Childhood, vol. 77, no. 1, pp. 32-37, 1997.

[16] T. Löppönen, E. Pääkkö, J. Laitinen, et al., "Pituitary size and function in children and adolescents with shunted hydrocephalus," Clinical Endocrinology, vol. 46, no. 6, pp. 691699, 1997.

[17] F. Cholley, C. Trivin, C. Sainte-Rose, J. C. Souberbielle, G. Cinalli, and R. Brauner, "Disorders of growth and puberty in children with non-tumoral hydrocephalus," Journal of Pediatric Endocrinology and Metabolism, vol. 14, no. 3, pp. 319-327, 2001.

[18] Y. W. Wu, C. T. Chin, K. M. Chan, A. J. Barkovich, and D. M. Ferriero, "Pediatric Chiari I malformations: do clinical and radiologic features correlate?" Neurology, vol. 53, no. 6, pp. 1271-1276, 1999.

[19] R. S. Tubbs, J. C. Wellons III, M. D. Smyth, et al., "Children with growth hormone deficiency and Chiari I malformation: a morphometric analysis of the posterior cranial fossa," Pediatric Neurosurgery, vol. 38, no. 6, pp. 324-328, 2003.

[20] R. L. Murphy, R. S. Tubbs, P. A. Grabb, and W. J. Oakes, "Chiari I malformation and idiopathic growth hormone deficiency in sinblings," Child's Nervous System, vol. 22, pp. 632-634, 2006.

[21] H. R. Weidemann and J. Kunze, Clinical Syndrome: Crouzon Syndrome, Times Mirror International, London, UK, 1995.

[22] P. M. Abou-Sleiman, A. Apessos, J. C. Harper, P. Serhal, and J. D. A. Delhanty, "Pregnancy following preimplantation genetic diagnosis for Crouzon syndrome," Molecular Human Reproduction, vol. 8, no. 3, pp. 304-309, 2002.

[23] C.-P. Chiang, L. Wan, C.-H. Tsai, C.-C. Lee, and F.-J. Tsai, "Mutation analysis of Crouzon syndrome in Taiwanese patients," Journal of Clinical Laboratory Analysis, vol. 20, no. 1, pp. 23-26, 2006. 